\title{
Efficient construction of the motorway and highway bridge superstructure (experimental studies)
}

\author{
Vladimir Babayev ${ }^{1}$, Mark Bekker ${ }^{1}$, Valeriy Shmukler ${ }^{1 *}$, Sergey Bugayevskiy ${ }^{2}$, Roman \\ Kaplin $^{1}$, and Yuriy Krul ${ }^{2}$ \\ ${ }^{1}$ O.M.Beketov National University of Urban Economy in Kharkiv, 61002, Kharkiv, \\ Marshal Bazhanov str., 17, Ukraine \\ ${ }^{2}$ Kharkiv National Automobile and Highway University, 61002, Kharkiv, Yaroslava \\ Mudrogo str., 25, Ukraine
}

\begin{abstract}
The design of the span structure of the bridge was presented. Its structure was formed by the creation of a composite steel and concrete element consisting spatial steel perforated boxlike-section blocks, a system of shear links of a special type and a monolithic reinforced concrete slab containing inside emptiness-formers The novelty of the design and methods of its creation predetermined the need for experimental testing. It was implemented in full-scale conditions and had, in addition to research, acceptance nature. In this connection, the article presents the results of tests of the composite steel and concrete structure of the superstructure of the bridge over Sukhoy Torets in Barvenkovo. The nature of its deformation under the static and dynamic loads is shown. During the tests, the components of the stress-strain state were determined at the distinguished points of the structure, fixed under static load. The amplitude and frequency response of the bridge unit were established for various dynamic impact options. Based on the obtained data, the structural resistance features under load impacts was analyzed, the design model of the bridge was verified, and the compliance of the accepted design parameters with the limitations of the applicable reference documents was confirmed.
\end{abstract}

\section{Introduction}

Most bridges of Ukraine were built in the 1950s and 1960s. Due to the considerable service life and abnormal operation, a large part of these structures have defects and damage to the superstructure elements, which significantly reduce the durability and load-carrying capacity of the entire structure. Many bridges have a non-standard span under the current classification. When such span structures need to be replaced, the issue arises of choosing an alternative design, which generally should be superior at least to the known standard solutions of the past years.

\footnotetext{
* Corresponding author: konstruktsii@gmail.com
} 


\subsection{Initial data}

The bridge over the river Sukhoy Torets was built in 1955. The structure was designed as a 4-span reinforced concrete plate-girder structure. The main girders of the span structure are made of reinforced concrete, with the nonstandard span $14.06 \mathrm{~m}$. The overall width of the roadway is $7.0 \mathrm{~m}$. The bridge piers are solid, concrete, with a steel and concrete pier cap. The distance between the pier axes is $14.1 \mathrm{~m}$. The total length of the bridge was $56.4 \mathrm{~m}$. The design load at the time of construction of the structure was N-13, NG-60. The overall view of the bridge is shown in the figure 1.

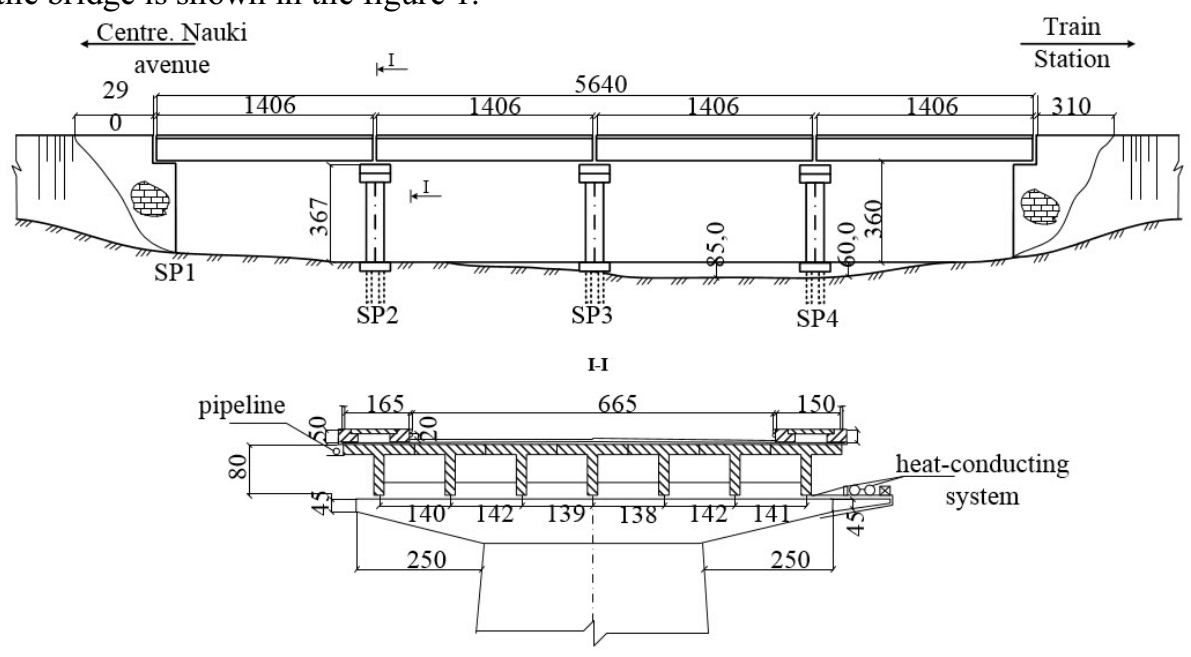

Fig. 1. The diagram of the overall view of the bridge over Sukhoy Torets in Barvenkovo.

Heavy military equipment that moved on the bridge resulted in a deflection up to $15 \mathrm{~cm}$ in the span structure, although it did not collapse. Cracks with a width of more than $10 \mathrm{~mm}$ appeared on the main girders of the superstructure. The construction was classified as the 5th operational condition, i.e. the bridge was estimates as non-operable. Major overhaul with the replacement of all superstructures became necessary for its further operation. Since the bridge piers were in satisfactory condition, the girders were replaced on the existing piers, with their partial restoration and reinforcement.

\subsection{Construction solution}

Due to the non-standard length of the span, a two-component system was suggested for use as a new superstructure, which could be produced according to individual dimensions without significant extra labour intensity during the manufacture and installation of the structure. The superstructure is a steel-reinforced concrete structure consisting of perforated metal units of the boxlike-section and a steel-reinforced concrete carriageway slab laid on the nonremovable formwork made of corrugated sheet [1]. This construction is a modification of the shell-type bridge superstructure system [2]. Unlike the prototype, in the caisson shell crosssection of this superstructure, four blocks with transverse spreading were installed at a distance of $2.4 \mathrm{~m}$ (between the axes of adjacent units). The units were combined into a single superstructure by arrangement of a $200 \mathrm{~mm}$ thick reinforced concrete slab. The slab is made of $\mathrm{C} 20 / 25$ grade concrete. The supports made of the rectangular pipe and inclined reinforcing bars are welded to the upper unit flanges to ensure the joint performance of metal units with a reinforced concrete carriageway slab. These elements, together with the connected 
reinforcing mesh of the slab, are a spatial shear link system that ensures efficient performance of the steel-reinforced concrete structure.

The cross-section and the overall view of the new superstructure are shown in Figure 2.
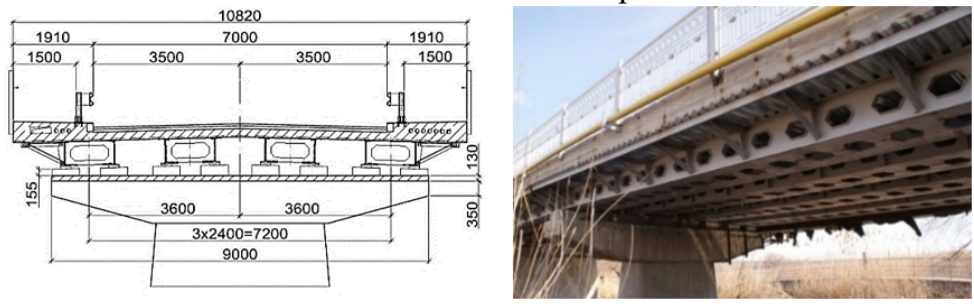

Fig. 2. Steel-reinforced concrete superstructure of the bridge over the river Sukhoy Torets in Barvenkovo.

As indicated above, the superstructure units have a boxlike section (Fig. 3). Elements of the units were made of perforated sheet steel of grade $15 \mathrm{XCНД.} \mathrm{Non-waste} \mathrm{technology} \mathrm{was}$ applied for manufacture of all perforated elements of the units. The unit structure includes two walls (main girders), a lower plate and transverse diaphragms. The diaphragm spacing is $1 \mathrm{~m}$. The unit wall thickness is $10 \mathrm{~mm}$, the bottom plate wall thickness is $30 \mathrm{~mm}$, and the diaphragm wall thickness is $12 \mathrm{~mm}$.
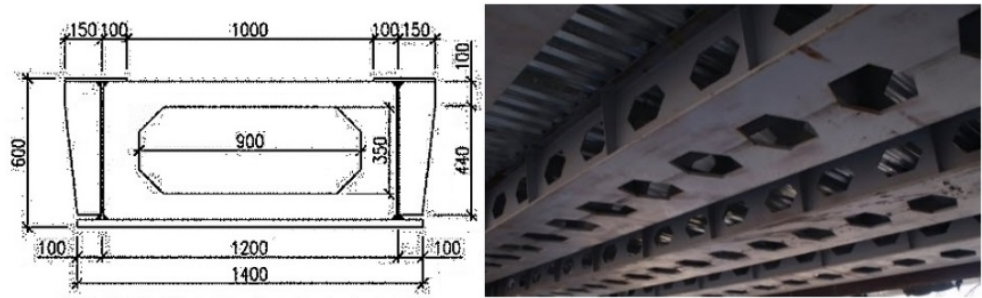

Fig. 3. Construction of metal units of the steel-reinforced concrete bridge superstructure.

The working design of the steel-reinforced concrete bridge superstructure was elaborated at the Department of Building Constructions of Beketov National University of Urban Economy (Kharkiv) for A-15, NK-100 load. All construction work was performed by Stalkonstruktsia LLC.

In Table 1, material consumption required for production of one span of the steelreinforced concrete superstructure is summarized. Specifications of the steel and concrete (standard design series 3.503-14) and metal (standard design series 3.503.9-43/89) superstructures are also given here for comparison.

Table 1. Materials consumption for the bridge superstructures.

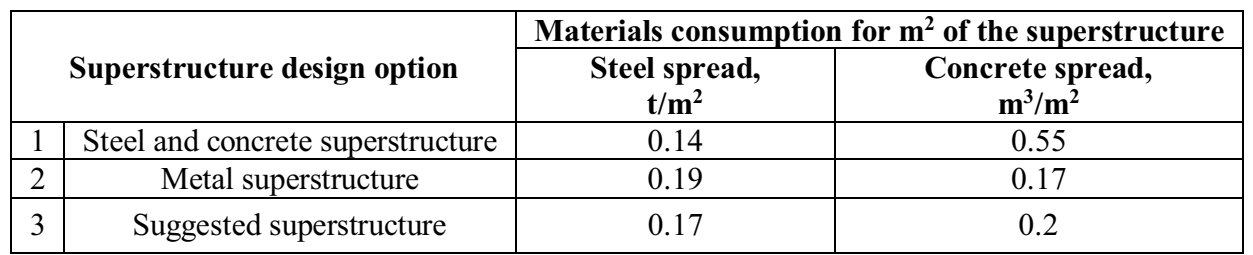

\section{Tests}

Researchers of the Department of Building Constructions of Beketov National University of Urban Economy in Kharkiv performed static and dynamic tests for study and acceptance of the construction. 
Test object - steel-reinforced concrete superstructure of the bridge over the river Sukhoy Torets in Barvenkovo.

Test objective - evaluation of stress-strain state components in the distinguished points of the superstructure unit under static load, as well as determination of amplitudes and frequencies of self-induced and forced vibrations of the unit under dynamic impact.

The following research tasks were fulfilled to achieve the above test objectives:

- measuring deflections in the distinguished points of the construction;

- measuring deformations and determination of actual stresses occurring in the distinguished unit cross-sections;

- comparing experimental and theoretical data for the stress-strain state components (verification of the design finite element model); and

- measuring frequencies and the corresponding amplitudes of their self-induced and forced vibrations, and consequent establishment of the possibility of resonance occurrence.

\subsection{Loading system}

Two loaded KAMAZ-6520 dump trucks were accepted as a test load. The vehicles were weighted before testing. The reference weight of each vehicle was $Q=19.2 \mathrm{t}$. During testing, the vehicles were placed on the superstructure in accordance with the previously proved and accepted loading patterns (within the testing program).

During the static part of testing, four load arrangement patterns were provided:

- placing a dump truck with its rearmost axle in the middle of the span near the right safety fence (Fig. 4);

- placing two dump trucks with their tailgates adjacent to each other, near the right safety fence (Fig. 5);
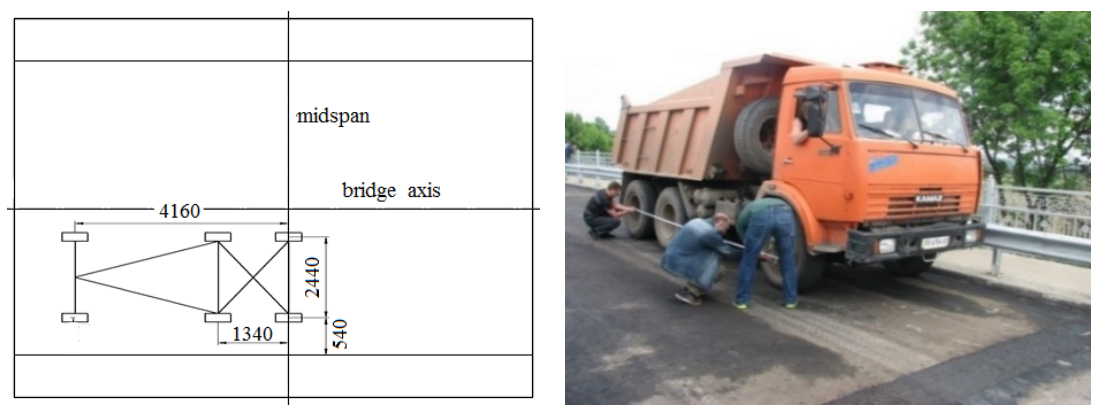

Fig. 4. First static load position pattern.
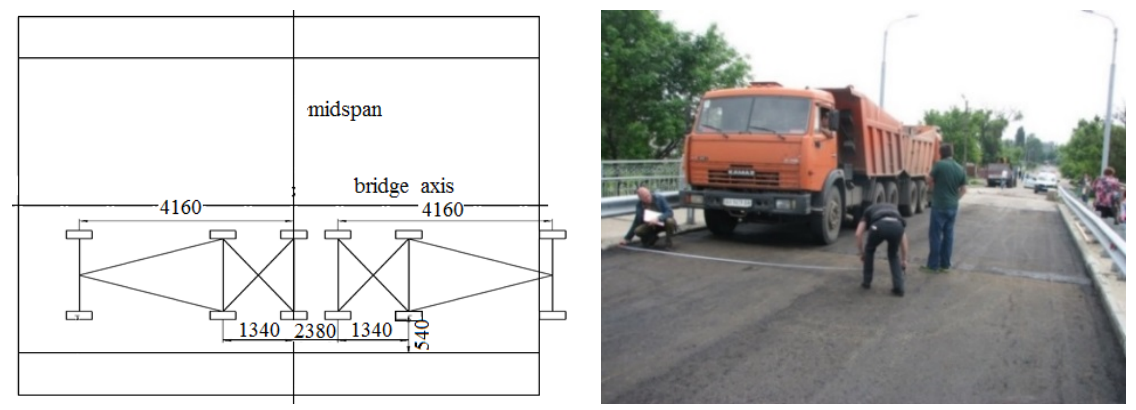

Fig. 5. Second static load position pattern.

- placing two dump trucks with their tailgates adjacent to each other, along the bridge axis (Fig. 6); 
- placing two dump trucks with their tailgates adjacent to each other, near the left safety fence (Fig. 7).
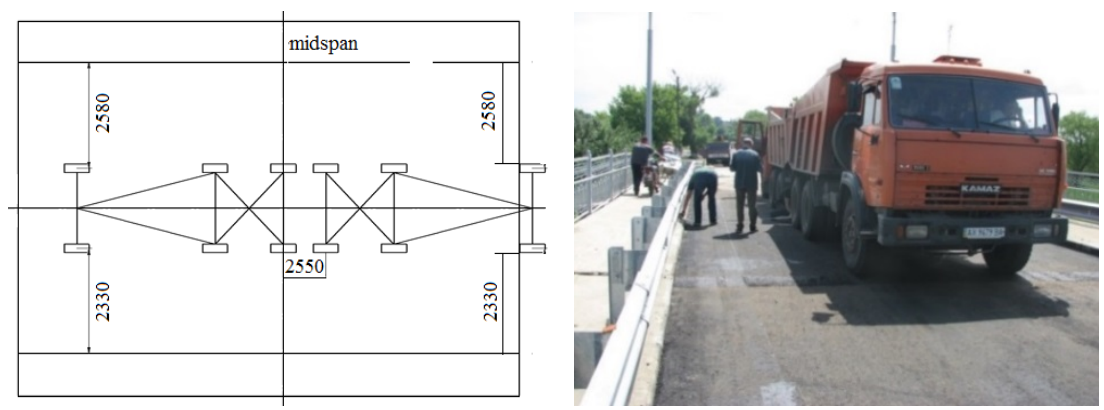

Fig. 6. Third static load position pattern.
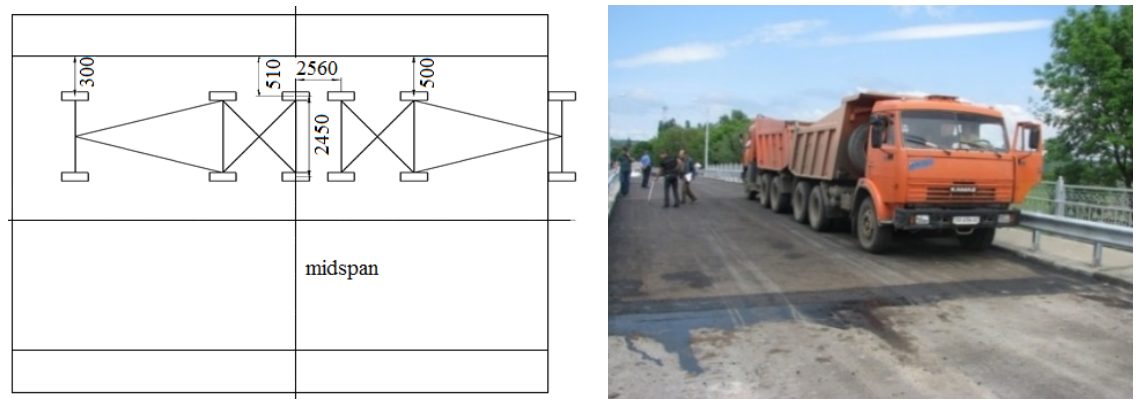

Fig. 7. Forth static load position pattern.

Once the vehicles were placed, the tests performing researchers were monitoring closely the readings of the meters in order to stop loading, if necessary (case of emergency). Changes in the state of the bridge were recorded without load, during loading and during subsequent unloading. The final measurements were made to determine the permanent deformations in the structure.

During the dynamic part of testing, the characteristics of self-induced and forced vibrations of the superstructure were determined. Self-induced vibrations per se occur when the span structure is operating in the free vibration mode after the shock impact. The dynamic effect of the shock load was studied by dropping a weight of $1 \mathrm{t}(85 \times 48 \times 55 \mathrm{~cm}$ foundation block) from the height of $1.2 \mathrm{~m}$ onto the carriageway.

A temporary load in the form of vehicles which corresponds to the actual mode of operation of bridges was used to determine the characteristics of forced vibrations. The test program provides the following options of dynamic impact:

- movement of a column of two KamAZ-6520 dump trucks at a speed of $40 \mathrm{~km} / \mathrm{h}$ and a 2second traffic interval;

- movement of a single dump truck at a speed of $40 \mathrm{~km} / \mathrm{h}$ over the road surface with an obstacle (a wooden bar $20 \mathrm{~cm}$ wide, $4 \mathrm{~cm}$ thick and $3.5 \mathrm{~m}$ long, palced in the middle of the span); and

- movement of a single dump truck at a speed of $40 \mathrm{~km} / \mathrm{h}$ and sharp braking in the middle of the span.

\subsection{Measurement system}

During the static part of testing, values of vertical displacements (deflections), as well as axial and transverse deformations of the elements of the metal unit of the steel-reinforced concrete superstructure were recorded. 
Deflections of the structure were recorded using 6-PAO-0,1 Maximov mechanical deflection meters. The principle of operation is that the measured movement of the monitored object is transmitted via the transmission chain (string) to the driving unit and further via the transmission mechanism to the arrow (Fig. 8). One end of the string is fixed directly on the monitored structure or on a rigid frame, hitched with at least one loop over the drive unit and pulled by the load. Deviation of the arrow relative to the scale and the arrow rotation indicator enable to determine the value of the measured movement. The transmission chain assembled from the weights and threads was maintained in constant tension to prevent the influence of external force factors and was checked before each reading.

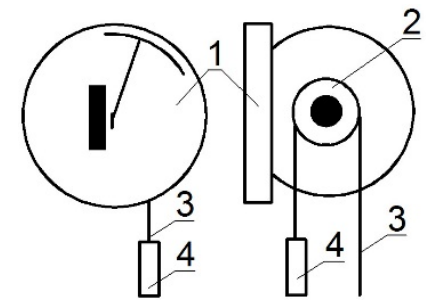

Fig. 8. Instrument arrangement diagram: 1 - Maximov deflection meter, 2 - roller, 3 - thread, 4 - load.

The deflection meters were fixed to the unit in the bearing parts, in the quarters and in the middle of the span. The instruments were arranged on the preliminarily prepared horizontal grounds using mount pillars and clamps. Two instruments were arranged in the quarters and in the middle of the span to record possible twisting on the unit. Deflection meter arrangement diagram and overall view are shown in Figure 9.
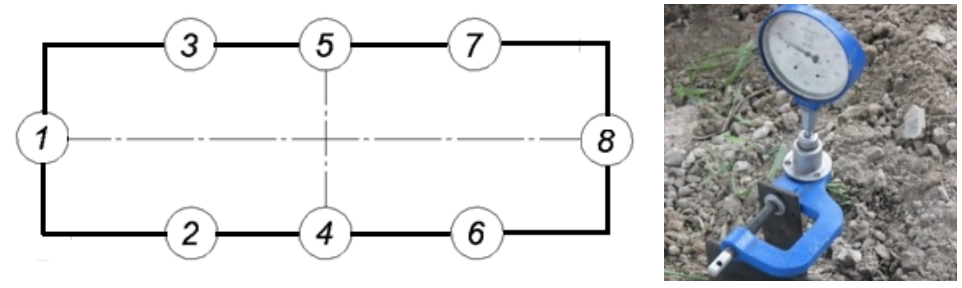

Fig. 9. Deflection meter arrangement diagram and overall view.

Gugenberger mechanical strain gauges were used to record deformations occurring in the walls of the metal unit. The gauges were arranged around the orifices, in the bearing part and in the middle of the span. The paint coat was removed on the prearranged grounds for installation of the instruments to detect deformations of the metal walls of the unit. Gauge arrangement diagram and overall view are shown in Figures 10-11.
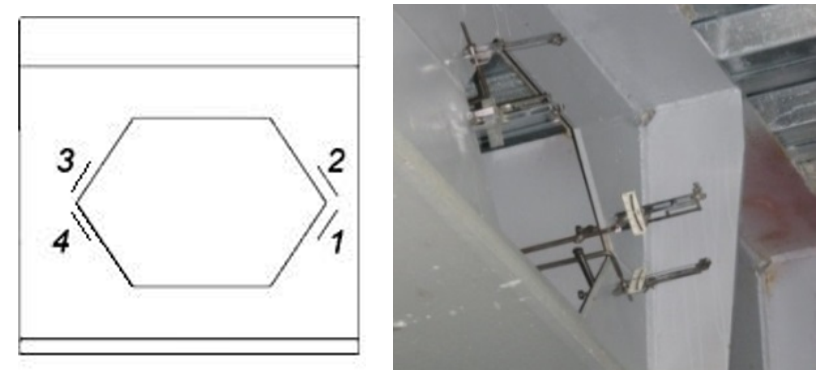

Fig. 10. Gauge arrangement diagram and overall view in the bearing part of the unit. 

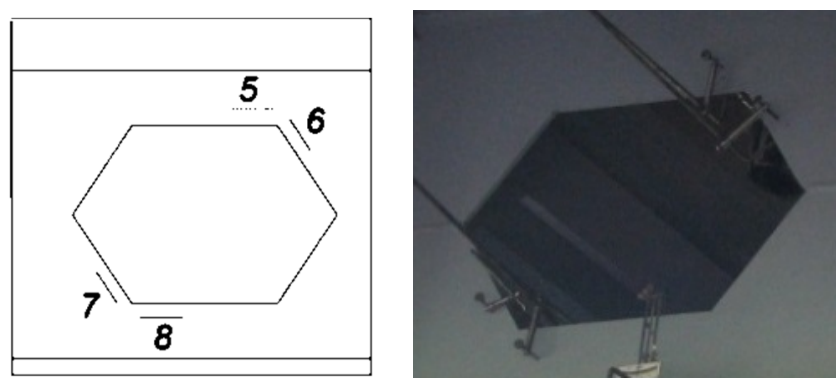

Fig. 11. Gauge arrangement diagram and overall view in the middle of the span.

Self-induced and forced vibration characteristics of the superstructure were determined using AGAT-M portable vibration analyzer. Using this instrument as a data collector together with DIAMANT-2 software enabled to obtain the amplitude frequency response (AFR) of the superstructure under different dynamic impact conditions by means of the built-in function of complex vibration expansion using discrete Fourier transformation.

\subsection{Preparatory stage of the experimental testing}

The following preparatory works were performed before testing:

- study of the physical and mechanical characteristics (properties) of the constituent materials of the constructions;

- theoretical analysis of the construction behaviour under action of the static test load.

The non-destructive method with OMSh-1 scratch hardness tester was used to determine concrete characteristics. The determined concrete grade is $\mathrm{C} 20 / 25$. Concrete deformation diagram is allowed to be presented as seventh power polinomial [3]:

$$
\sigma=\alpha_{1} \varepsilon+\alpha_{3} \varepsilon^{3}+\alpha_{5} \varepsilon^{5}+\alpha_{7} \varepsilon^{7}
$$

Unknown coefficients in (1) can be expressed in terms of the the material deformation characteristics [3]:

$$
\begin{gathered}
\alpha_{3}=\frac{\varepsilon_{u}^{4}}{2\left(\varepsilon_{u}^{2}-\varepsilon_{R}^{2}\right)^{2}}\left[\frac{1}{\varepsilon_{R}^{2}}\left(\frac{R}{E_{0} \varepsilon_{R}}-1\right)\left(5-7 \frac{\varepsilon_{R}^{2}}{\varepsilon_{u}^{2}}\right)-\frac{1}{\varepsilon_{R}^{2}}\left(\frac{\varepsilon_{R}^{2}}{\varepsilon_{u}^{2}}-1\right)+\frac{2 \varepsilon_{R}^{4}}{\varepsilon_{u}^{6}}\left(\frac{\beta R}{E_{0} \varepsilon_{u}}-1\right)\right] \\
\alpha_{5}=\frac{\varepsilon_{u}^{4}}{2\left(\varepsilon_{u}^{2}-\varepsilon_{R}^{2}\right)^{2}}\left[\frac{1}{\varepsilon_{R}^{4}}\left(7 \frac{\varepsilon_{R}^{2}}{\varepsilon_{u}^{2}}-3\right)\left(\frac{R}{E_{0} \varepsilon_{R}}-1\right)-\frac{1}{\varepsilon_{R}^{4}}\left(1-\frac{\varepsilon_{R}^{4}}{\varepsilon_{u}^{4}}\right)+\frac{4 \varepsilon_{R}^{2}}{\varepsilon_{u}^{6}}\left(\frac{\beta R}{E_{0} \varepsilon_{u}}-1\right)\right] \\
\alpha_{7}=\frac{\varepsilon_{u}^{4}}{2\left(\varepsilon_{u}^{2}-\varepsilon_{R}^{2}\right)^{2}}\left[\frac{1}{\varepsilon_{R}^{4} \varepsilon_{u}^{2}}\left(\frac{R}{E_{0} \varepsilon_{R}}-1\right)\left(3-5 \frac{\varepsilon_{R}^{2}}{\varepsilon_{u}^{2}}\right)-\frac{1}{\varepsilon_{R}^{4} \varepsilon_{u}^{2}}\left(\frac{\varepsilon_{R}^{2}}{\varepsilon_{u}^{2}}-1\right)+\frac{2 \varepsilon_{R}^{4}}{\varepsilon_{u}^{6}}\left(\frac{\beta R}{E_{0} \varepsilon_{u}}-1\right)\right]
\end{gathered}
$$

where $E_{0}$ - initial stress-strain modulus; $\varepsilon_{R}$ - compressive strain in the concrete at the peak stress; $\varepsilon_{u}$ - ultimate strain; $R$ - strength limit; $\beta R$-stress corresponding to the ultimate strain. Laboratory tests of the standard metal test plates were performed to evaluate mechanical characteristics of the steel. Steel grade was determined to be $15 \mathrm{XCНД,} \mathrm{which} \mathrm{proved} \mathrm{the}$ design characteristics.

Concrete and steel deformation diagrams were plotted using the obtained data (Fig. 12). 
a)

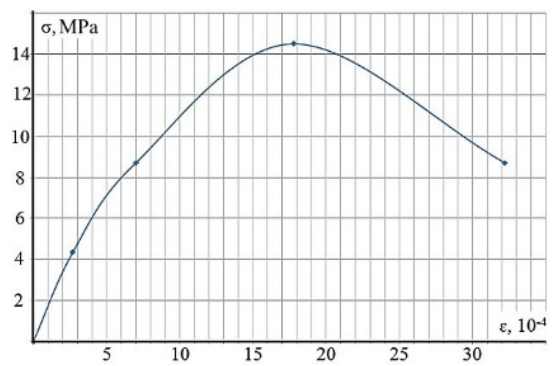

b)

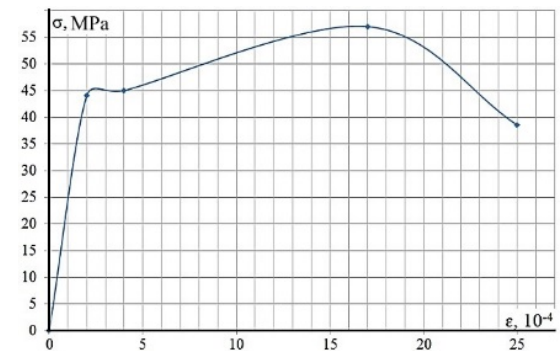

Fig. 12. Material deformation diagrams: a) for concrete; b) for steel.

Theoretical calculations were performed in the SCAD Office environment, with preliminary building of a finite-element model of the superstructure. The superstructure construction was simulated with shell elements of zero Gaussian curvature, bumpers - with special rod elements. Reference mobile loads (A-15 and NK-100) and static test load were chosen as loads in accordance with the accepted loading patterns. The structural design of the suggested superstructure is shown in Figure 13.

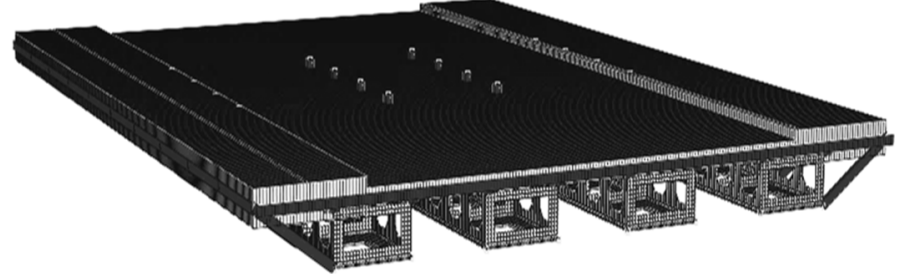

Fig. 13. Structural design of the superstructure.

With the span length $14.06 \mathrm{~m}$, the greatest stress in the superstructure will evidently be caused by load NK-100 located in the middle of the span along the bridge axis. The maximum deflection of the construction, with an allowance for the dead weight, is $28.1 \mathrm{~mm}$, which is $1 / 498$ of the span length (Fig. 14). The deflection caused by the dead weight of the construction was $17.1 \mathrm{~mm}$. Maximum stress (in the lower flange) was $2,384 \mathrm{~kg} / \mathrm{cm}^{2}$, minimum stress (in the upper flange) was $550 \mathrm{~kg} / \mathrm{cm}^{2}$ (Fig. 15).

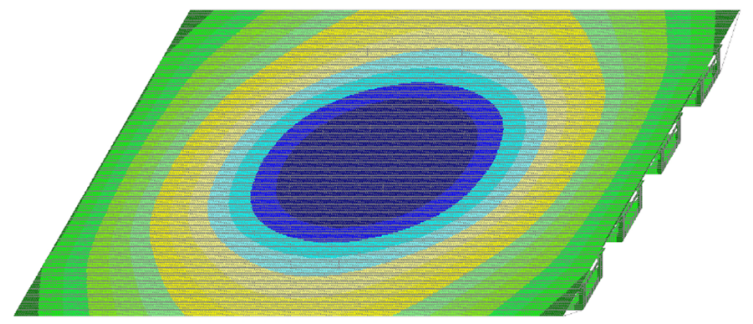

Fig. 14. Isofield of vertical displacement of the construction.

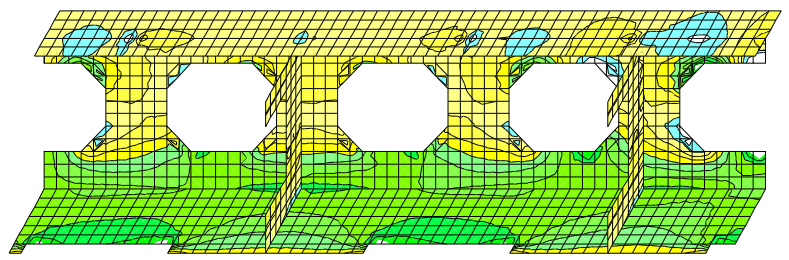

Fig. 15. Isofield of normal stresses in the superstructure (fragment). 
Values of vertical displacements of the constructions and principal stresses in the crosssections of the unit were obtained during calculation of the superstructure for the test load. The obtained theoretical computation data are summarized in Table 2 as isofields of vertical displacement and isofields of main stresses.

Maximum deflection of the construction in the middle of the span of $3.04 \mathrm{~mm}$ was obtained with the second static loading pattern. The stress values at the corners of orifices and in the concentration points did not excess $250 \mathrm{~kg} / \mathrm{cm}^{2}$.

\section{Test data}

\subsection{Static test data}

Construction deflection lines were plotted for all 4 static loading patterns based on processing of the values measured with deflection meters and theoretical data obtained during computation (Fig. 16 to 19).

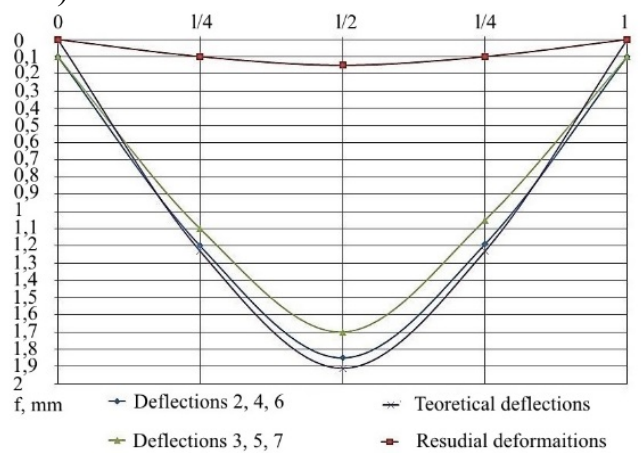

Fig. 16. Structural deflections (first pattern).

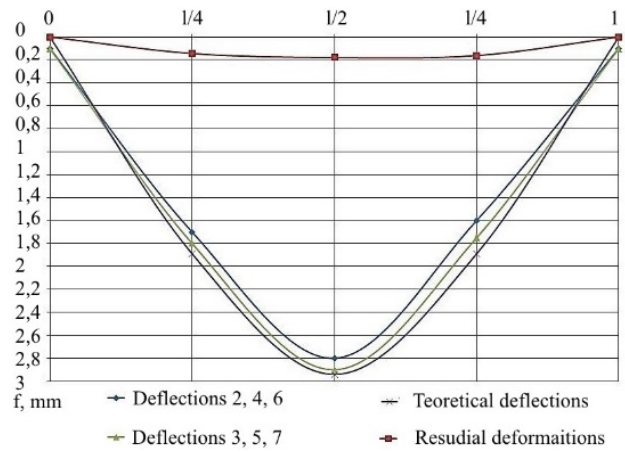

Fig. 17. Structural deflections (second pattern).

Maximum test deflection was recorded with the 2 nd load pattern $f=2.9 \mathrm{~mm}$. No unit twisting was recorded. Permanent deformations recorded after unloading (for each load) did not exceed $10 \%$. Discrepancy of the obtained test data with the theoretical deflections did not exceed $5 \%$.

The deformations measured with mechanical strain gauges are summarized in Table 2. 


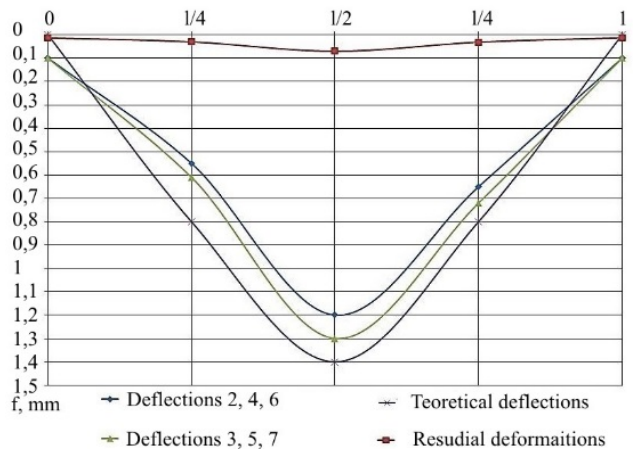

Fig. 18. Structural deflections (third pattern).

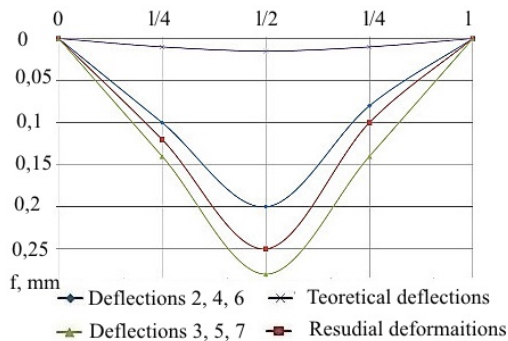

Fig. 19. Structural deflections (forth pattern).

Table 2. Deformation values measured with mechanical strain gauges.

\begin{tabular}{|c|c|c|c|c|c|c|c|c|}
\hline $\begin{array}{c}\text { Load } \\
\text { pattern }\end{array}$ & $\begin{array}{c}\varepsilon 1, \\
\mathrm{~mm} \cdot 10^{-4}\end{array}$ & $\begin{array}{c}\varepsilon_{2}, \\
\mathrm{~mm} \cdot 10^{-4}\end{array}$ & $\begin{array}{c}\varepsilon_{3}, \\
\mathrm{~mm} \cdot 10^{-4}\end{array}$ & $\begin{array}{c}\varepsilon_{4} \\
\mathbf{m m} \cdot 10^{-}\end{array}$ & $\begin{array}{c}\varepsilon_{5} \\
\underset{4}{\mathrm{~mm}} \cdot \mathbf{1 0}^{-}\end{array}$ & $\begin{array}{c}\varepsilon_{6}, \\
\mathbf{m m} \cdot 10^{-}\end{array}$ & $\begin{array}{c}\mathbf{\varepsilon} 7 \\
\mathbf{m m} \cdot 10^{-}\end{array}$ & $\begin{array}{c}\varepsilon s \\
\mathbf{m m} \cdot 10\end{array}$ \\
\hline Pattern 1 & 0.6 & 0.6 & 0.6 & 0.6 & 0.78 & 0.78 & 0.78 & 0.78 \\
\hline Pattern 2 & 0.82 & 0.79 & 0.78 & 0.79 & 1 & 0.8 & 1 & 0.8 \\
\hline Pattern 3 & 0.67 & 0.67 & 0.67 & 0.67 & 0.79 & 0.79 & 0.79 & 0.79 \\
\hline Pattern 4 & 0 & 0 & 0 & 0 & 0.25 & 0.25 & 0.25 & 0.25 \\
\hline
\end{tabular}

Actual stress values occurring in the tested cross-sections of the unit were calculated using the " $\sigma-\varepsilon "$ diagram (Table 3). Point numbering was accepted as shown in Figures 10 and 11.

Table 3. Stress values obtained using the diagram " $\sigma-\varepsilon$ ".

\begin{tabular}{|c|c|c|c|c|c|c|c|c|}
\hline $\begin{array}{c}\text { Load } \\
\text { pattern }\end{array}$ & $\begin{array}{c}\sigma_{1}, \\
\mathrm{~kg} / \mathrm{cm}^{2}\end{array}$ & $\begin{array}{c}\sigma_{2}, \\
\mathrm{~kg} / \mathrm{cm}^{2}\end{array}$ & $\begin{array}{c}\sigma_{3}, \\
\mathrm{~kg} / \mathrm{cm}^{2}\end{array}$ & $\begin{array}{c}\sigma_{4}, \\
\mathrm{~kg} / \mathrm{cm}^{2}\end{array}$ & $\begin{array}{c}\sigma_{5}, \\
\mathrm{~kg} / \mathrm{cm}^{2}\end{array}$ & $\begin{array}{c}\sigma_{6}, \\
\mathbf{k g} / \mathrm{cm}^{2}\end{array}$ & $\begin{array}{c}\sigma 7 \\
\mathrm{~kg} / \mathrm{cm}^{2}\end{array}$ & $\begin{array}{c}\sigma 8, \\
\mathrm{~kg} / \mathrm{cm}^{2}\end{array}$ \\
\hline Pattern 1 & 150 & 150 & 150 & 150 & 180 & 180 & 180 & 180 \\
\hline Pattern 2 & 200 & 185 & 180 & 185 & 250 & 195 & 250 & 195 \\
\hline Pattern 3 & 160 & 160 & 160 & 160 & 185 & 185 & 185 & 185 \\
\hline Pattern 4 & 0 & 0 & 0 & 0 & 50 & 50 & 50 & 50 \\
\hline
\end{tabular}

Maximum relative deformation value $1 \cdot 10^{-4} \mathrm{~mm}$ corresponds to the stress value of $250 \mathrm{~kg} / \mathrm{cm}^{2}$. The error in comparison of the experimental and theoretical stress values was $5-10 \%$.

\subsection{Dynamic test data}

During the dynamic part of testing, amplitude frequency response (AFR) of the superstructure unit under different dynamic impacts were obtained. The diagram describing the dependence of amplitudes from the self-induced vibration frequencies is shown in Figure 20. 


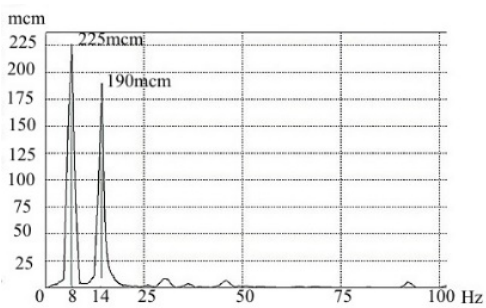

Fig. 20. Self-induced vibration frequency range.

Two peaks at vibration frequency $8 \mathrm{~Hz}$ (amplitude $225 \mu \mathrm{m}$ ) and $14 \mathrm{~Hz}$ (amplitude $190 \mu \mathrm{m})$ can be seen on the self-induced vibration frequency range. These frequencies correspond to period $0.019 \mathrm{sec}$ and $0.011 \mathrm{sec}$, respectively, which do not fall into the prohibited range $0.45 \leq T \leq 0.6 \mathrm{sec}$.

Any gradually damped oscillatory motions of the system after the impulse excitation can be described with the formula:

$$
y(t)=A_{0} e^{-\delta \cdot t} \sin (2 \pi f t)
$$

where $y(t)$ - value of displacement of the oscillating body; $A_{0}$ - initial vibration amplitude; $f$ - vibration frequency; $\delta$ - attenuation coefficient.

However, attenuation coefficient cannot describe completely the attenuation intensity. Therefore, as it is known, logarithmic decrement of vibrations is introduced to characterize the attenuation intensity [5]. In view of the connection of the attenuation coefficient with the frequency $\delta=d \cdot f_{0}$ and attenuation coefficient with the amplitude frequency response of the vibratory system $\delta=\pi \cdot \Delta f$, logarithmic decrement can be expressed as follows:

$$
d=\pi \frac{\Delta f}{f_{0}}
$$

where $f_{0}$ - vibration frequency at the maximum amplitude; $\Delta f$ - bandpass of the vibratory system at 0.707 of the maximum.

Characteristics of the self-induced vibrations are given in Table 4.

The obtained values of the self-induced vibration decrement are consistent with those for the steel-reinforced concrete bridges.

The diagram describing the dependence of amplitudes from the forced vibration frequencies under different dynamic impact options with the mobile load are shown in Figures 21-23.

Table 4. Characteristics of the self-induced vibrations of the superstructure.

\begin{tabular}{|c|c|c|}
\hline $\begin{array}{c}\text { Self-induced vibration } \\
\text { frequency, } \mathrm{Hz}\end{array}$ & $\begin{array}{c}\text { Self-induced vibration period, } \\
\mathrm{sec}\end{array}$ & $\begin{array}{c}\text { Self-induced vibration } \\
\text { decrement }\end{array}$ \\
\hline 8 & 0.019 & 0.043 \\
\hline 14 & 0.011 & 0.049 \\
\hline
\end{tabular}

Only one strongly pronounced peak stands out on the forced vibration frequency ranges. Also, forced vibration frequencies vary within the range of 5 to $12.5 \mathrm{~Hz}$, while the recorded amplitudes do not excess $80 \mathrm{~mm}$. 


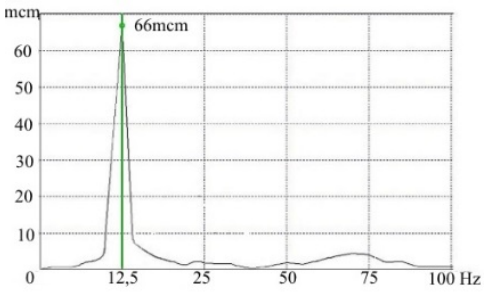

Fig. 21. Forced vibration frequency range (pattern 1).

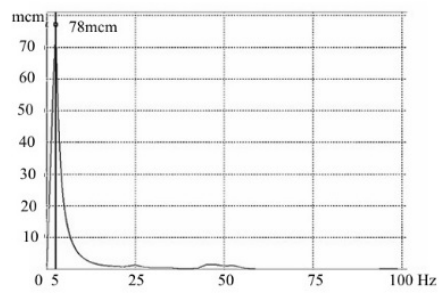

Fig. 22. Forced vibration frequency range (pattern 2).

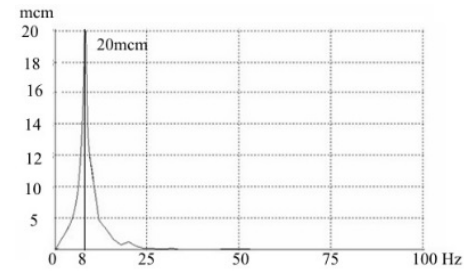

Fig. 23. Forced vibration frequency range (pattern 3).

The frequency range defining virtual resonance vibration modes, in its turn, can be assigned as $\pm 20 \%$ change of self-induced vibration frequencies (at least, for the fundamental period). Thus, the prohibited range for the forced vibration frequencies is:

$$
0,8 \omega \leq f \leq 1,2 \omega
$$

where $f$-forced vibration frequency; $\omega$ - self-induced vibration frequency.

Substituting successively the measured self-induced vibration frequency values into the in inequation (4) we can notice that:

- the prohibited forced vibration range lies within the range of 6.4 to $9.6 \mathrm{~Hz}$ and 11.2 to $16.8 \mathrm{~Hz}$;

- the forced vibration frequencies of the bridge superstructure unit are within the prohibited range when loaded by the first and third mobile dynamic load pattern.

Nevertheless, occurring resonance can be considered non-dangerous, if the deflection from the static load and dynamic extra load does not exceed the estimated deflection from the reference load multiplied by the dynamic coefficient [6]. Based on the quoted approach we can write the safety condition for the resonance:

$$
y_{L / 2}+A<<y(1+\mu)
$$

where $A$ - frequency amplitude; $y$ - maximum deflection of the construction from the reference load; $y_{L / 2}$ - static deflection in the middle of the span from the considered load; $1+\mu$-amplification factor (rated value for the steel-reinforced concrete bridges is accepted as $1+\mu=1.4)$. 
Is it was mentioned above, maximum estimated deflection of the construction caused by reference load NK-100 is (without accounting for the dead weight of the construction) $y=11 \mathrm{~mm}$. Static deflection when a vehicle is placed in the middle of the span is $y_{L / 2}=2 \mathrm{~mm}$.

Substituting the data obtained for the first and third dynamic loading patterns to the left and right parts of the inequation (5), we can obtain:

- for the first pattern $y_{L / 2}+A=2+0.066=2.066 \mathrm{~mm}$ and $y(1+\mu)=11 \cdot 1.4=15.4 \mathrm{~mm}$, i.e. $2.066 \mathrm{~mm}<<15.4 \mathrm{~mm}$;

- for the third pattern $y_{L / 2}+A=2+0.02=2.02 \mathrm{~mm}$ and $y(1+\mu)=11 \cdot 1.4=15.4 \mathrm{~mm}$ and, as consequence, $2.02 \mathrm{~mm}<<15.4 \mathrm{~mm}$.

The inequations are evidently fulfilled very safely. It shows that none of the mentioned dynamic impacts cannot sway the bridge up to dangerous amplitude values.

Based on the conducted studies, we can conclude that:

- the values of actual deflections of the structure of the steel-reinforced concrete superstructure in the quarters and middle of the tested span were determined. The maximum experimental deflection was recorded for the 2 nd loading pattern $\mathrm{f}=2.9 \mathrm{~mm}$. No unit twisting was recorded. The permanent deformations recorded after unloading at each loading stage did not exceed $10 \%$;

- the values of the actual stresses occurring at the corners of the orifices on the walls of the metal unit were calculated based on the processed deformation values obtained using mechanical strain gauges and laboratory tests for determination of mechanical characteristics of steel. The stress value of $250 \mathrm{~kg} / \mathrm{cm}^{2}$ corresponds to the maximum value of relative deformations of $0.15 \cdot 10^{-4} \mathrm{~mm}$. The permanent deformations recorded after unloading at each loading stage did not exceed $10 \%$;

- the error in comparison of the experimental and theoretical stress values was $5-10 \%$. Thus, the calculated finite element model of the superstructure was verified;

- during the dynamic part of testing, amplitude-frequency response (AFR) of the superstructure unit were obtained for different dynamic impact options and diagrams of the spectral characteristics of self-induced and forced vibrations were built. The vibrations are damped. The logarithmic decrement of self-induced vibrations of the superstructure is within the range $0.043-0.049$. The fulfilment of the safety condition of the resonance occurring in the first and third dynamic impact patterns was estimated. The safety condition is fulfilled with large tolerance.

The obtained results enabled to commission the bridge in May 2016.

\section{References}

1. Y.N. Krul: Kommunalnoe khozyaystvo gorodov, 101, 31-40 (2011).

2. V. Shmukler, M. Shutkin, B. Shutkin, Y. Krul Patent 74599 MPK (2012.01) E01D 1/00 Ukraine (2012).

3. V. Shmukler Zbirnik naukovyh pratc Ukrainian state university of railway transport, 167, 54-69 (2017)

4. N. Bezukhov, O. Luzhin, N. Kolkunov A manual for specialized construction universities. 3-rd edition, Moscow, High scool, 264 (1987).

5. G. Atabekov Textbook for universities. 3-rd edition, ispr. i dop., Moscow: Energy, 319, (1966)

6. L. Khazanov Issledovanie moctovykh i tonnelnnykh soorygeniy, Moscow, 101-111 (2006). 